Warmelink, J.C., Hoijtink, K., Noppers, M., Wiegers, T.A., Cock, T.P. de, Klomp, T., Hutton, E.K An explorative study of factors contributing to the job satisfaction of primary care midwives. Midwifery: 2015, 31(4), 482-488

\begin{tabular}{|l|l|}
\hline $\begin{array}{l}\text { Postprint } \\
\text { Version }\end{array}$ & 1.0 \\
\hline Journal website & http://www.midwiferyjournal.com/article/S0266-6138(14)00298-8/abstract \\
\hline Pubmed link & $\underline{\text { http://www.ncbi.nlm.nih.gov/pubmed/25600327 }}$ \\
\hline DOI & $10.1016 /$ j.midw.2014.12.003 \\
\hline
\end{tabular}

This is a NIVEL certified Post Print, more info at http://www.nivel.eu

\title{
An explorative study of factors contributing to the job satisfaction of primary care midwives
}

\author{
J. CATJA WARMELINK, MSC ${ }^{\text {A, B, }}$ (PSYCHOLOGIST (LECTURER)), KiRSTEN HOIJTINK, RN, \\ BM, RM ${ }^{\mathrm{B}, 1}$ (MidWIFE), MARloes NopPERs, RN, BM, RM ${ }^{\mathrm{B}, 1}$ (MidWIFE), THERESE A. \\ Wiegers, PhD ${ }^{\mathrm{C}}$ (SENior Researcher), T. PAUl de CoCK, PhD ${ }^{\mathrm{A}, \mathrm{B}}$ (SENiOR \\ RESEARCHER), TRUdY KLOMP, RM, MSC ${ }^{\mathrm{A}, \mathrm{B}}$ (LECTURER), EILEEN K. HUTTON, BSC, \\ MScN, PhD ${ }^{A, D}$ (Assistant DeAn, Director MidWifery, Professor Obstetrics \\ AND GyNECOLOGY, PROFESSOR MiDWIFERY SCIENCE)
}

\begin{abstract}
Objective: the main objectives of our study was to gain an understanding of how primary care midwives in the Netherlands feel about their work and to identify factors associated with primary care midwives' job satisfaction and areas for improvement.

Design: a qualitative analysis was used, based on the constructivist/interpretative paradigm. Three open-ended questions in written or online questionnaire, analysed to identify factors that are linked with job satisfaction, were as follows: 'What are you very satisfied with, in your work as a midwife?', 'What would you most like to change about your work as a midwife?' and 'What could be improved in your work?'.

Setting: 20 of the 519 primary care practices in the Netherlands in May 2010 were included.

Participants: at these participating practices 99 of 108 midwives returned a written or online questionnaire.

Findings: in general, most of the participating primary care midwives were satisfied with their job. The factors positively associated with their job satisfaction were their direct contact with clients, the supportive co-operation and teamwork with immediate colleagues, the organisation of and innovation within their practice group and the independence, autonomy, freedom, variety and opportunities that they experienced in their work. Regarding improvements, the midwives desired a reduction in non-client-related activities, such as paperwork and meetings. They wanted a lower level of work pressure, and a reduced case-load in order to have more time to devote to individual clients' needs. Participants identified that co-operation with other partners in the health care system could also be improved.
\end{abstract}


Warmelink, J.C., Hoijtink, K., Noppers, M., Wiegers, T.A., Cock, T.P. de, Klomp, T., Hutton, E.K An explorative study of factors contributing to the job satisfaction of primary care midwives. Midwifery: 2015, 31(4), 482-488

Key conclusions: our knowledge, our study is the first explorative study on factors associated with job satisfaction of primary care midwives. While there are several studies on job satisfaction in health care; little is known about the working conditions of midwives in primary care settings. Although the participating primary care midwives in the Netherlands were satisfied with their job, areas for improvement were identified. The results of our study can be relevant for countries that have a comparable obstetric system as in the Netherlands, or are implementing or scaling up midwifery-led care.

\section{INTRODUCTION}

In the Netherlands, the primary care midwife is an independent medical professional, comparable to a general practitioner (GP), whose autonomy is authorised in the 'Individual Health Care Profession Act' (in Dutch: Wet op de Beroepen in de Individuele Gezondheidszorg: de Wet BIG) (Ministry of Health, Welfare and Sport, 2013). Primary care midwives provide care to healthy women with uncomplicated pregnancies throughout their pregnancy, labour and six-weeks post partum. In cases where increased risk, complications or interventions during pregnancy or labour and birth (as defined by national guidelines) arise, women are referred to an obstetrician. In 2012, 84.9\% of all pregnant women in the Netherlands received care in early pregnancy by a primary care midwife, $52.4 \%$ started labour under supervision of a primary care midwife, and $30.4 \%$ of all births $(n=173,099)$ were supervised by a primary care midwives at home or in a homelike setting in a hospital or birth centre ( The Netherlands Perinatal Registry, 2013). At the time of our study, in 2010, 73.8\% of 2568 practicing midwives worked in a primary care setting across 519 midwifery practices, as a self-employed practitioner, employee or locum ( Hingstman and Kenens, 2013 and van Hassel and Wiegers, 2014). Most of the midwives (98.4\%) are female ( Hingstman and Kenens, 2013).

The primary care midwives in the Netherlands are working in a profession with many factors affecting the demand, supply and content of professional practice. In the last decades, many midwifery practices merged to become larger with more midwives per practice (Hingstman and Kenens, 2013). According to the Royal Dutch Association of Midwives (KNOV) the social and organisational context in which midwives are working, is becoming increasingly complex (KNOV, 2010). A current debate focuses on ways to reduce the perinatal death rate by improving the quality of care (Stuurgroep, 2009). For that reason, all midwifery practices are expected to participate in a local maternity care consultation and co-operation group (in Dutch: Verloskundig Samenwerkings Verband or VSV) with the local hospital and work with protocols and guidelines. Different models of organisation of midwifery care are envisioned in the Netherlands, for instance a system of integrated midwifery care (de Vries et al., 2013).

Job satisfaction is known to play an important part in any decision to leave the job. Diminished job satisfaction is important to turnover intentions of allied health care professionals, such as (hospital) nurses (Coomber and Barriball, 2007, Lee and Cummings, 2008, Lu et al., 2012 and Homburg et al., 2013), and medical professionals, such as GPs and physicians (McComb, 2008 and Zhang and Feng, 2011). High levels of job satisfaction are protective against stress, have a positive impact on self-esteem, and may be involved in increasing motivation for self- 
Warmelink, J.C., Hoijtink, K., Noppers, M., Wiegers, T.A., Cock, T.P. de, Klomp, T., Hutton, E.K An explorative study of factors contributing to the job satisfaction of primary care midwives. Midwifery: 2015, 31(4), 482-488

development (d'Archard van Enschut, 2012). Individual levels of work engagement of midwives in maternity hospitals were linked with the midwives' health and selfreports of the quality of care (Freeney and Fellenz, 2013). Job satisfaction has also been associated with the practitioner's health, as well as health and safety of their patients in a study of women physicians (Rizvi et al., 2012).

Among caregivers in the Netherlands some studies on job satisfaction have been done (van der Hulst, 1993; van Ham et al., 2006, Wiegers and Janssen, 2006 and Maurtis et al., 2012). Nurses and social workers who are less satisfied with their jobs, often feel less able to work until pension age than caregivers who are more satisfied with their jobs (Maurtis et al., 2012). Factors related to increased job satisfaction among GPs in the Netherlands included diversity of work, relations and contact with colleagues, and being involved in teaching medical students. Factors related to decreased job satisfaction among GPs were (relatively) low income, too many working hours, administrative burdens, heavy workload, lack of time, and lack of recognition (van Ham et al., 2006).

Job satisfaction among midwives in the Netherlands has also been assessed in a number of studies. van der Hulst (1993) concluded that job satisfaction of midwives was higher with home births than with births supervised in hospitals. The overall job satisfaction of primary care midwives in the Netherlands, measured on the 5-point scale by Boumans et al. (1989) was relatively high and has increased from 4.03 in 2001, to 4.07 in 2002-2003 and 4.12 in 2004 (Wiegers and Janssen, 2006). However, little is known about which factors are associated with job satisfaction among primary care midwives in the Netherlands and areas that midwives identify for improvement or change. If factors - favourably or adversely - affecting job satisfaction for primary care midwives are extrinsic, these may be modifiable. Furthermore, within the shifts in the Dutch midwifery system toward an 'integrated model of care' (de Vries et al., 2013), job satisfaction among midwives is important to inform future policy regarding integrated model of care.

The aim of this exploratory study was to gain an understanding of how primary care midwives feel about their work and investigate factors associated with job satisfaction of primary care midwives in the Netherlands. The research questions of this study were:

1. What are primary care midwives very satisfied with, in their work as a midwife?

2. What would primary care midwives most like to change or improve in their work as a midwife?

3. Is there a difference between midwives who stated to be satisfied compared to midwives who stated to be less satisfied?

\section{METHODS}

\section{Study design}

This study used data on midwifery practices from the DELIVER study (Manniën et al., 2012). The DELIVER study was a multicentre prospective dynamic cohort study aimed at evaluating primary midwifery care in the Netherlands with a focus on quality, organisation and accessibility of care. 
Warmelink, J.C., Hoijtink, K., Noppers, M., Wiegers, T.A., Cock, T.P. de, Klomp, T., Hutton, E.K An explorative study of factors contributing to the job satisfaction of primary care midwives. Midwifery: 2015, 31(4), 482-488

\section{Recruitment and enrolment of study participants}

Purposive sampling was used in the DELIVER-study to recruit 20 of the 519 primary care practices in the Netherlands. Three stratification criteria were used in practice selection: practice type (dual or group practice), level of urbanisation (urban or rural area) and region (north, centre, and south). Fourteen practices declined participation mostly because of time constraints. For each a replacement was found taking region, urbanisation and practice type into account. Each participating practice signed a contract through which they gave consent to co-operate with all parts of the study. The initial sample consisted of 108 midwives, working in the 20 participating midwifery practices.

\section{Data collection}

In order to explore baseline information, personal and work related characteristics and job satisfaction, in May 2010 written or online questionnaires were distributed among the midwives $(N=108)$ at the participating practices. The DELIVER research team asked the practices to give a reminder to midwives who did not complete and return the questionnaire within two weeks.

The following baseline information was collected: gender, job-type (self-employed practitioners, employees or locum), practice type (group or dual practice), country of midwifery education, work experience (in years), and age. A section of the questionnaire focused on the midwives' job satisfaction. The question 'To what extent are you satisfied with your work' measured job satisfaction on 4-point Likert scale. This variable 'satisfied with your work' was dichotomized in satisfied (score 1 'very satisfied' and 2 'satisfied') and less satisfied (score 3 'varying satisfied' and 4 'not satisfied'). Three open-ended questions were used to identify factors associated with job satisfaction and what midwives would like to see changed in their work, as follows: 'What are you very satisfied with, in your work as a midwife?', 'What would you most like to change about your work as a midwife?' and 'What could be improved in your work?'.

\section{Data analysis}

Descriptive analyses were used to describe characteristics of the study population. Qualitative analysis of the three open-ended questions was based on the constructivist/interpretative paradigm (assuming reality is subjective and human beings construct their own social realities in relation to one another) (Boeije, 2008, p. 18). Three researchers, trained in the qualitative approach (two student midwives $\mathrm{KH}$ and $\mathrm{MN}$ under supervision of $\mathrm{CW}$ ) independently undertook the analyses. Data were categorised into themes by each researcher, using content analysis (Tong et al., 2007 and Boeije, 2008). The process started with a systematic line-by-line analysis to derive codes. Coded responses were then categorised and grouped into broader themes. Definitions of codes, categories and themes were created and discussed until consensus was reached on the findings and with reflections on the research process and the role of the researchers. We looked for possible new meanings and connections and recommendations for practice. Detailed notes were taken during this analysis. The coding tree is illustrated in Box 1. For each theme exemplifying quotations, identified with the practice number (range 01-20) and respondent number within the practice (range 01-10) [in brackets], were selected to illustrate the results. The quotes were translated into English by an accredited translator, and then 
Warmelink, J.C., Hoijtink, K., Noppers, M., Wiegers, T.A., Cock, T.P. de, Klomp, T., Hutton, E.K An explorative study of factors contributing to the job satisfaction of primary care midwives. Midwifery: 2015, 31(4), 482-488

translated back in Dutch by another investigator (TW) in order to check for validity of translation.

We compared responses on the open ended questions in two subgroups of participating midwives: those who indicated they were satisfied or very satisfied on the 4-point scale question 'To what extent are you satisfied with your work'; and those who scored as less satisfied or not satisfied.

\section{Ethical approval and privacy issues}

This study was approved by the Medical Ethics Committee of the VU University Medical Centre Amsterdam. Privacy was guaranteed in accordance with Dutch legislation. Midwives' anonymity was maintained by using anonymous practice and personal identifiers.

\section{FINDINGS}

\section{Baseline characteristics of participants}

Overall, 99 (91.7\%) of the 108 primary care midwives invited to participate completed the questionnaire. Most participants (99.0\%) were female. The midwives were working in private practices, either as self-employed practitioners (72.7\%), as employees (18.2\%) or in locum positions (9.1\%). A few (4.0\%) worked together with one colleague in a duo-practice, $96.0 \%$ worked in group practices (practices with more than two midwives). 84.5\% were educated in the Netherlands and 15.5\% elsewhere (Belgium, the UK). The mean age of the participants was 37.5 years $(S D=10.0$; range $22-61$ years) and the mean working years was 12.7 years $(S D=9.9$; range $0-40$ years). On the 4-point scale question 'To what extent are you satisfied with your work', 31.3\% stated that they were very satisfied (score 1); 51.5\% satisfied (score 2), 17.2\% less satisfied (score 3) and none not satisfied (score 4).

\section{Factors related to job satisfaction}

Analysis of the answers to the open ended question 'What are you very satisfied with, in your work as a midwife?' revealed four aspects of the work that generated satisfaction: (1) direct contact with clients, (2) supportive co-operation and teamwork, (3) the organisation of and innovation within the practice where one works and (4) aspects of the work itself such as work pleasure, autonomy and variety.

Direct contact with clients and clients' satisfaction with midwifery care make a major contribution to job satisfaction according the participating midwives. Midwives mentioned 'the contact with clients', and 'the satisfaction expressed by clients'. One midwife stated: 'The possibility of giving people the support they need at the most beautiful moment of their life' [18\#04].

Good, supportive contacts with colleagues - especially immediate colleagues within the midwifery practice - were appreciated and contributed to satisfaction among midwives. Phrases like, 'being on good terms with colleagues', 'co-operation', 'good colleagues' and 'the midwifery team' were mentioned in responses. One midwife used the expression: 'Good relations within the partnership' [10\#06]. Another stated: 'I work with fantastic colleagues who always give me the support I need, who are always there when I have questions and who were an enormous support when I first started work in the practice' [20\#04]. Co-operation within the health care system and with secondary care providers was noticed: 'Good co-operation with healthcare partners makes the work much easier' [02\#02]. 
Warmelink, J.C., Hoijtink, K., Noppers, M., Wiegers, T.A., Cock, T.P. de, Klomp, T., Hutton, E.K An explorative study of factors contributing to the job satisfaction of primary care midwives. Midwifery: 2015, 31(4), 482-488

Midwives generally appreciated characteristics of the practice where they worked. The phrase 'organisation of the practice' occurred in the responses. One midwife expressed satisfaction with her well organised practice: 'Everything is well organised in our practice, which improves the quality of the care we can offer clients: there's enough room to work; the right protocols, good work schedules, backup, extra time to discuss breastfeeding with the clients (more than once, if necessary)'[17\#04]. Midwives also appreciated the scope for innovation and development within the practice. For example, midwives mentioned: 'the possibility for innovation in midwifery practice' [10\#06]; 'the ability to learn about new developments' [10\#02]; and 'exploring new avenues and implementing new services such as preconception care, ultrasound scans and information for clients' [02\#05].

Midwives indicated clearly that they enjoyed the work itself, and that the independence, autonomy, freedom, variety and opportunities they experienced in their work were aspects they appreciated: 'the satisfaction I get from the work as such' [14\#03]; 'my autonomy' [07\#03]; 'there's a lot of variety in my work, which gives me a great deal of satisfaction' [10\#03]; and 'I've got the job of a lifetime; I've had it for the past 28 years' [09\#03].

\section{Areas for improvement}

The two open ended questions 'What would you most like to change about your work as a midwife?' and 'What could be improved in your work?' were grouped together, because the content of the answers was comparable. Although there may be a difference in necessity or urgency with these two questions, it was not discernible in the answers of our participants.

Responses to these questions fell into three categories: (1) aspects of the work not directly related to care for clients, (2) aspect of work directly related to care for clients and (3) the personal workload.

\section{Aspects of the work not directly related to care for clients}

Midwives described some of the tasks that are not directly related to the care for clients as 'a burden' and 'time-consuming' that detracted them from the primary focus of midwifery. Those tasks comprise: paperwork and co-operation and communication with immediate colleagues and with other disciplines, including meetings. Midwives saw such tasks as something they had to devote too much of their 'own time' to. For example, one midwife stated: 'There's too much to do, I'm overloaded and there are too many different tasks. I want more balance between the time I can devote to clients and the time I have to spend on other tasks' [13\#06]. The paperwork midwives must complete is described as 'red tape' [13\#07], 'bureaucracy for the sake of bureaucracy' [06\#01] and 'administrative nuisance' [03\#01]. While midwives can see the necessity of these administrative tasks, they would like to see the amount of time they have to spend on them reduced or to have them performed by someone else. Another comment made in connection with the necessary paperwork is that they think they should be paid extra for these administrative tasks. One midwife made the following comment: 'I spend much too much time on administrative matters and those related to the practice and further training. I would prefer to spend more time on direct patient care' [15\#01]. It was also felt that co-operation and communication both with immediate colleagues and with other health care disciplines could be improved. The midwives indicated that they would like to see changes in the division of tasks and operational methods 
Warmelink, J.C., Hoijtink, K., Noppers, M., Wiegers, T.A., Cock, T.P. de, Klomp, T., Hutton, E.K An explorative study of factors contributing to the job satisfaction of primary care midwives. Midwifery: 2015, 31(4), 482-488

within the midwifery practice itself: 'Communication with colleagues within the practice could be better' [01\#02], and 'More uniformity in policy; work more together as one team' [18\#04]. It was also indicated that more should be done to improve co-operation with general practitioners (GPs) and other disciplines such as maternity care assistants (in Dutch: kraamverzorgenden) and youth health care in order 'to join forces in primary care' [14\#02]. Better co-operation with secondary care providers (consultants such as obstetricians and paediatricians) was emphasised, where a need was expressed for better, respectful communication. Comments here included: 'better contacts are needed' [17\#03]; 'cooperation should be better and more unambiguous' [05\#05]; 'communication should be more open and respectful' [10\#05]; and 'with understanding for one another's discipline' [17\#02]. Another respondent believed that there should be more integration with secondary care with regards to knowledge and training: 'A trainee obstetrician should spend some time working in primary care; that's the only way to appreciate the full scope of maternity care' [11\#01]. Evening meetings were described as 'time-consuming' and 'excessive'. These descriptions applied both to discussions with immediate colleagues (consultations within the practice) and to meetings with other disciplines such as those in the local maternity care consultation and co-operation group (in Dutch: Verloskundig Samenwerkings Verband or VSV) and perinatal audits. Midwives' opinions were divided about quality assurance and knowledge translation. On the one hand, the importance of quality assurance of care and knowledge translation was underlined and it was suggested that more time should be spent on this. More research in primary care midwifery was mentioned as one way of ensuring high quality. One midwife commented: 'More and more research is being done in this field at present, but the results are not always applied in practice' [12\#08]. On the other hand, not everyone agreed with policy agreements and guidelines both within the practice and at a national level. One midwife commented: 'All those guidelines you have to follow and boxes you have to tick... it almost gets too much for me sometimes!' [05\#02]. Another stated, 'This increasing tendency to force us to work according to rigid guidelines should be abolished' [03\#01].

\section{Aspects of the work directly related to care for clients}

A need was expressed for working 'on a smaller scale' [12\#09], so as to make it possible to devote more time to individual client's needs. Midwives wanted to have more time to spend on fewer clients. Getting to know the clients and putting them at the centre of midwifery care were also regarded as important: 'I want to deliver more personal care, and that means more time for my clients' [07\#03], 'I want to have time to really support the mother during child birth' [03\#03], 'I wish I had fewer clients so that I could offer each one the full care and attention she needs' [18\#04]. The midwives made a plea for home births: 'Research has shown that home birth is safe. Please let us maintain this beautiful Dutch tradition' [20\#04].

\section{Personal workload}

Midwives wanted to reduce their workload. 'Reduce the high workload,' 'less work pressure' and 'cut the working hours' were commonly written comments. It was mentioned that 'midwives take on a lot of extra work' [13\#09], 'there's always something I have to do' [05\#02] and that the 'work-life balance' is sometimes hard to find. The on-call hours that had to be worked, the irregularity of the work and the 
Warmelink, J.C., Hoijtink, K., Noppers, M., Wiegers, T.A., Cock, T.P. de, Klomp, T., Hutton, E.K An explorative study of factors contributing to the job satisfaction of primary care midwives. Midwifery: 2015, 31(4), 482-488

frequent need to work nights were also seen as factors that make the work 'heavy': 'the additional on-call periods, I find them very hard' [12\#01]. In line with this, midwives would like to see the on-call periods made shorter (' $12 \mathrm{~h}$ instead of 24 , for example' [15\#01]).

\section{Comparison between satisfied midwives and less satisfied midwives}

We compared responses of the 82 very satisfied and satisfied midwives (scores 1 and 2 on the question 'To what extent are you satisfied with your work' ) with those of the 17 less satisfied (scores 3 and 4) midwives, and found no remarkable difference in their responses. Most topics were mentioned by both groups, although in general the satisfied midwives gave more detailed explanations and were more positive about the possibilities for innovation and development in midwifery practice.

\section{Discussion}

This exploratory study identified factors that contributed to or detracted from job satisfaction reported by primary care midwives in the Netherlands. In a time when midwifery is in flux and when there are so many suggestions for potential structural change to how midwifery is organised, job satisfaction is an important ingredient in the total mix.

In general, the participating primary care midwives in the Netherlands were satisfied with their work. Our qualitative analysis of open-ended questions revealed that midwives were very pleased with their direct contact with clients, the supportive cooperation and teamwork with immediate colleagues, the organisation of and innovation within the practice where they work and the independence, autonomy, freedom, variety and opportunities they experienced in their work. To improve the work, midwives would like reduced non-client-related activities, such as paperwork and meetings, less work pressure, reduced case-loads and more time to devote to individual clients' needs. Better co-operation with partners in secondary care or with other partners in the health care system were also identified as areas that would improve the work.

\section{Comparison with other research}

It is difficult to compare this study on job satisfaction of Dutch primary care midwives with studies of job satisfaction of hospital midwives and nurses abroad (Lee and Cummings, 2008 and Lu et al., 2012), because of the different scope of the occupational roles (nursing versus midwifery; community midwifery versus hospital midwifery). However, compared with the study of Castanda and Scanlan (2014) the job satisfaction of hospital nurses as well as our primary care midwives were related to autonomy, interpersonal relationships and patient care. Todd et al. (1998) examined job satisfaction of community midwives in the UK, and reported some results similar to our study. The community midwives as well as our participating midwives reported that their job was satisfying, that they liked the variety of the work and disliked the long on call hours and the poor work-life balance. Compared with the study of Rizvi et al. (2012) on women physicians in the United States both our participating midwives and the women physicians were concerned with perceived lack of time for their own family and relationships with patients. Compared with the study of van Ham et al. (2006) on job satisfaction among Dutch general practitioners, both primary care midwives and GPs were pleased with the content of their work and the relation and contact with direct colleagues. Similar to 
Warmelink, J.C., Hoijtink, K., Noppers, M., Wiegers, T.A., Cock, T.P. de, Klomp, T., Hutton, E.K An explorative study of factors contributing to the job satisfaction of primary care midwives. Midwifery: 2015, 31(4), 482-488

participants in our study, the GPs found their workload too high and administration burden too heavy.

Our present study points out that primary care midwives had a high perceived work pressure and case-load, even after the reduction of the number of 'care units' in January 2010 from 120 to 105 (NZa, 2009), and wanted to spend less time on nonclient-related activities and more time with the client. This feeling corresponds with the results of the study by Wiegers et al. (2014) that midwives worked on average more hours in 2010 compared to 2004 or 2001, and spent an increasing proportion of their time on non-client-related activities. So, although non-client related activities such as administrative tasks and consultation with other care providers are an essential part of the midwives' job, the balance between these activities and direct client care may need to be reconsidered.

National projects are being undertaken to enhance interprofessional relationships and better communication between all maternity care providers and the client (CPZ, 2014). Financial barriers, lack of confidence in each other, disagreements in philosophy and about the content of multidisciplinary guidelines and anxiety about giving up one's autonomy are bottlenecks to come to a more closer co-operation or a more integrated model of care (CPZ, 2014). Problems with workload or work-life balance were not explicitly mentioned as bottlenecks.

Three important elements of the job of primary care midwives in the Netherlands need to be highlighted: the autonomy in the work, the work-life balance and the percentage of home births. Autonomy is an important feature in the work of the independent primary care midwife and has been identified as a determinant of job satisfaction in our study and other studies (Tyssen et al., 2013, Castaneda and Scanlan, 2014 and Hunter and Warren, 2014). Most of the midwives were female, and next to work related factors, more personal characteristics, like having young children at home, or lacking work-life balance can have an impact on feelings of job satisfaction (Emancipatiemonitor, 2012, Rizvi et al., 2012 and Robinson, 1993). It may be that perspectives and opportunities for midwives' career advancement are influenced by gender issues in families and organisations. For Dutch primary care midwives, when a higher percentage of the supervised birth occurred at the clients' own home instead of a hospital maternity wards, the chances of 'burnout' were lower (Bakker et al., 1996) and the job satisfaction higher (van der Hulst, 1993). These findings support the plea verbalised by one of the participating midwives to 'maintain the Dutch tradition of home birth'.

\section{Strengths and limitations}

To our knowledge, this is the first explorative study on factors related to job satisfaction of primary care midwives. Coding and analysis of the data by several researchers with different backgrounds and perspectives and discussing the interpretations (investigator triangulation) enhanced the reliability of these findings (Boeije, 2008, p. 152). Transparency in reporting and systematic reporting will enhance replicability of the study. The validity of this research is indicated by the response rate and sample size, with 99 of the 108 midwives (92\%) participating. According to the interpretivist/constructivist paradigm, we did rely upon the participants' view or interpretation of the situation studied and had no theory or hypothesis to start with (Mackenzie and Knipe, 2006). Generalisability has been enhanced by the participation of midwifery practices from various geographical locations in the country. 
Warmelink, J.C., Hoijtink, K., Noppers, M., Wiegers, T.A., Cock, T.P. de, Klomp, T., Hutton, E.K An explorative study of factors contributing to the job satisfaction of primary care midwives. Midwifery: 2015, 31(4), 482-488

There are limitations that must be considered in the interpretation of the results. Although we had a total number of 99 respondents, the respondents are clustered in 20 practices and so the observations are not independent of each other. In the DELIVER study there were no solo practices included, whereas $15.7 \%$ of all Dutch midwifery practices were solo practices in 2010, with $4.9 \%$ of all primary care midwives working solo (Hingstman and Kenens, 2013). Therefore, we missed the voices of solo-practicing midwives. Also, almost $14 \%(13.6 \%)$ of the primary care midwives were working in a dual practice in 2010 (Hingstman and Kenens, 2013) compared to the $4 \%$ in this study. In solo or dual practises the client care may be organised differently. Next, our study provides a preliminary examination of factors associated with job satisfaction using open-ended questions in questionnaire format. This approach does not allow for further probing of meaning or background of what was written, thus limiting the so-called 'thick description' (rich and detailed descriptions) of the context (Boeije, 2008, p. 131). The study design did not allow for dialogue between researchers and participants and so we were not able to 'negotiate truth through dialogue' and 'construct reality together', as sought-after in interpretivist/constructivist approaches (Mackenzie and Knipe, 2006). For example, we could not examine the concept of 'job satisfaction' or explore for the question 'What could be improved in your work', what the midwives themselves would do differently (e.g. self-improvement) or what they would like to change in their work environment. A richer exploration could be done with midwives using in-depth interviews, looking more closely at representations of context, experiences and issues in different types of midwifery employment.

Our study was conducted in the Netherlands, which has a strong community-based maternity care system with autonomous primary care midwives and a relatively high rate of 'natural' births as defined by the National Institute for Health and Clinical Excellence (NICE, 2007). The results of our study can be relevant for countries that have a comparable obstetric system, or are implementing or scaling up midwifery-led care (Members of Midwifery Science Work Group, 2013 and Klomp et al., 2014).

\section{Recommendations}

As a result of this study, some recommendations can be made. First, although nonclient related activities such as administrative tasks and consultation with other care providers are an essential part of the midwives' job, the balance between these activities and direct client care, or perhaps a certain lack of professional ambition, may need to be addressed. Midwives expressed concern that the quality of their care is impinged upon by time spent on these tasks. Also the co-operation and communications with partners in secondary care and with other partners in the health care system can be improved. Kennedy (2009) highlighted several elements essential for successful collaborative practice: open communication and information on all levels, decision making by consensus, role clarity, agreements to work toward pathways for collaboration, similar financial rewards, and non-hierarchical structures and rotating leadership. Finally, the autonomy in the work, the work-life balance and the tradition of home birth can be relevant in the discussion about job satisfaction of primary care midwives in the Netherlands.

In a time when midwifery is in flux and when there are so many suggestions for potential structural change to how midwifery is organised, job-satisfaction is an important ingredient in the total mix, also because job satisfaction plays an important part in any decision to leave the job. Going into the future, factors associated with 
Warmelink, J.C., Hoijtink, K., Noppers, M., Wiegers, T.A., Cock, T.P. de, Klomp, T., Hutton, E.K An explorative study of factors contributing to the job satisfaction of primary care midwives. Midwifery: 2015, 31(4), 482-488

job satisfaction and areas for improvement are important to address as part of the puzzle.

To our knowledge, this is the first explorative, qualitative study on factors related to job satisfaction of primary care midwives in the Netherlands and internationally. We would like to do further research to see how these factors are related to each other and gain more insight into factors directly influencing the job satisfaction experienced by primary care midwives. To achieve this, it is recommended that to do a more in-depth qualitative or quantitative research in a large study population, in which all forms of practices (solo, dual and group practices) are adequately represented and in which collaboration, autonomy in the work, work-life balance and the tradition of home birth are important elements.

\section{CONCLUSIONS}

In general, most participating primary care midwives in the Netherlands were satisfied with their job. Midwives were very pleased with their direct contact with clients, the supportive co-operation and teamwork with immediate colleagues, the organisation of and innovation within the practice where they work and the independence, autonomy, freedom, variety and opportunities they experienced in their work. Regarding improvements, the midwives wanted to reduce the non-clientrelated activities, such as paperwork and meetings. They wanted to lower the work pressure, reduce the case-load and have more time to devote to individual clients' needs. The co-operation with partners in secondary care and with other partners in the health care system can also be improved.

We recommended to do further more in-depth qualitative or quantitative research in a large study population, in which all forms of practices (solo, dual and group practices) are included.

\section{CONFLICT OF INTEREST}

The authors declare there are no competing interests.

\section{ETHICAL APPROVAL}

This study was carried out as part of the national DELIVER study, which obtained ethical approval by the Medical Ethics Committee of the VU University Medical Centre in Amsterdam, the Netherlands (WC 008-100).

\section{AUTHORS' CONTRIBUTION}

TW, TK and EH originated and supervised the DELIVER study and the recruitment the midwifery practices. $\mathrm{KH}$ and $\mathrm{MN}$ analysed the data under supervision of, $\mathrm{CW}$. $\mathrm{KH}, \mathrm{MN}$ and CW drafted the manuscript. All authors read and corrected draft versions of the manuscript and approved the final manuscript.

\section{ACKNOWLEDGEMENTS}

The authors are indebted to the midwives who participated in this study and the research assistances of DELIVER, Ruth Baron, Monique Pereboom and Myrte Westerneng. Furthermore, we would like to thank Paul van Wilgen for his contribution to earlier versions of this article. 
Warmelink, J.C., Hoijtink, K., Noppers, M., Wiegers, T.A., Cock, T.P. de, Klomp, T., Hutton, E.K An explorative study of factors contributing to the job satisfaction of primary care midwives. Midwifery: 2015, 31(4), 482-488

\section{APPENDIX A. SUPPLEMENTARY MATERIALS}

\section{REFERENCES}

R.H. Bakker, P.P. Groenewegen, L. Jabaaij, W. Meijer, H. Sixma, A. de Veer 'Burnout' among Dutch midwives Midwifery, 12 (1996), pp. 174-181

$\mathrm{H}$. Boeije Analyseren in kwalitatief onderzoek [Analysis in qualitative research] Boom Lemma Uitgevers, Den Haag (2008)

N.P.G. Boumans, J.A. Landeweer, J.H.M. Houtem Arbeidsvoldoening bij verpleegkundigen: factor- en betrouwbaarheidsanalyse [Job satisfaction among nurses: factor analysis and reliability] Tijdschrift voor Sociale Gezondheidszorg, 67 (1989), pp. 199-203

Castaneda, G.A., Scanlan, J.M., 2014. Job Satisfaction in Nursing: A Concept Analysis. Nursing Forum.

B. Coomber, K.L. Barriball Impact of job satisfaction components on intent to leave and turnover for hospital-based nurses: a review of the research literature Int. J. Nurs. Stud., 44 (2007), pp. 297-314

College Perinatale Zorg., 2014. Samenwerking in de geboortezorg: positieve ontwikkelingen, knelpunten en oplossingen [Cooperation in the maternity care: positive developments, problems and solutions] letter to the Ministry of Health, Welfare and Sport, 18 March 2014. 〈http://www.goedgeboren.nl/netwerk/Multimedia/Get/2394〉 . (last accessed 31 March 2014)

d'Achard van Enschut, E., 2012. Relatie tussen competentiebeleving en werktevredenheid van pedagogische medewerkers en hun professionele relatie met de kinderen [Relationship between perceived competence and job satisfaction of teaching staff and their professional relationship with the children]. Universiteit Utrecht.

R. de Vries, M. Nieuwenhuijze, S.E. Buitendijk, Members of Midwifery Science Work Group What does it take to have a strong and independent profession of midwifery? Lessons from the Netherlands Midwifery, 29 (2013), pp. 1122-1128

Emancipatiemonitor [Emancipation monitor] 2012. Sociaal en Cultureel Planbureau, Centraal Bureau voor de Statistiek [the Netherlands Institute for Social Research and Statistics Netherlands], the Hague.

Y. Freeney, M.R. Fellenz Work engagement as a key driver of quality of care: a study with midwives J. Health Organ. Manag., 27 (2013), pp. 330-349

Hingstman, L., Kenens, R.J., 2013. Cijfers uit de registratie van verloskundigen: peiling 2012 [Data from the registration of midwives 2012]. NIVEL, Utrecht.

V. Homburg, B. van der Heijden, L. Valkenburg Why do nurses change jobs? An empirical study on determinants of specific nurses' post-exit destinations J. Nurs. Manag., 21 (2013), pp. 817-826

B. Hunter, L. Warren Midwives' experiences of workplace resilience Midwifery, 30 (8) (2014), pp. 926-934

H.P. Kennedy "Orchestrating Normal": the conduct of midwifery in the United States F. Davis-Flyod, L. Barclay, B.-A. Daviss, J. Tritten (Eds.), Birth Models that Work, University of California Press, Berkeley, Los Angeles, London (2009)

T. Klomp, J. Manniën, A. de Jonge, E.K. Hutton, A.L. Lagro-Janssen What do midwives need to know about approaches of women towards labour pain management? A qualitative interview study into expectations of management of labour pain for pregnant women receiving midwife-led care in the Netherlands Midwifery, 30 (4) (2014), pp. 432-438

KNOV: Koninklijke Nederlandse Organisatie voor Verloskundigen [The Royal Dutch Organisation of Midwives]. Beroepsprofiel [Professional profile] (last accessed 11 June 2013)http://www.knov.nl/docs/uploads/Definitief_beroepsprofiel_versie_4_maart_2010.pdf

H Lee, G.G. Cummings Factors influencing job satisfaction of front line nurse managers: a systematic review J. Nurs. Manag., 16 (2008), pp. 768-783

H. Lu, K.L. Barriball, X. Zhang, A.E. While Job satisfaction among hospital nurses revisited: a systematic review Int. J. Nurs. Stud., 49 (2012), pp. 1017-1038

Mackenzie and Knipe, 2006 N. Mackenzie, S. Knipe Research dilemmas: paradigms, methods and methodology Issues Educ. Res., 16 (2006), pp. 193-205 
Warmelink, J.C., Hoijtink, K., Noppers, M., Wiegers, T.A., Cock, T.P. de, Klomp, T., Hutton, E.K An explorative study of factors contributing to the job satisfaction of primary care midwives. Midwifery: 2015, 31(4), 482-488

J. Manniën, T. Klomp, T. Wiegers, et al. Evaluation of primary care midwifery in the Netherlands: design and rationale of a dynamic cohort study (DELIVER) BMC Health Serv. Res., 12 (2012), p. 69

E.M. Maurtis, A.J.E. Veer de, AL. Francke Werkdruk en werktevredenheid van belang voor kunnen doorwerken tot pensioen [Workload and job satisfaction is important to be able to work until retirement] NIVEL, Utrecht (2012)

E.D. McComb Which psycho-demographic factors predict a doctor's intention to leave New Zealand general practice? N. Z. Med. J., 121 (2008), pp. 25-36

Ministry of Health, Welfare and Sport. BIG-register. [Individual Professions Healthcare Act] (last accessed 03 February 2013) 〈http://www.bigregister.nl〉

Nederlands Zorgautoriteit (NZa), 2009. Visiedocument eerstelijns verloskundige zorg; een advies over vrije prijsvorming [Vision paper primary midwifery care: advice on free-price setting]. (last accessed 07 April 2014) http://www.nza.nl/104107/10057/Visiedocument_Eerstelijns_verloskundige_zorg.pdf $\rangle$. NICE Clinical Guideline 55 Intrapartum Care: Care of Healthy Women and Their Babies During Childbirth National Collaborating Centre for Women's and Children's Health 7 (2007)

R. Rizvi, L. Raymer, M. Kunik, J. Fisher Facets of career satisfaction for women physicians in the United States: a systematic review Women Health, 52 (2012), pp. 403-421

$S$ Robinson Combining work with caring for children, findings from a longitudinal study of midwives' careers Midwifery, 9 (4) (1993), pp. 183-196

Stuurgroep zwangerschap en geboorte, 2009. Steering Group Pregnancy and Childbirth: A Safe Beginning. Safety in Care Concerning Pregnancy and Childbirth. Utrecht.

The Netherlands Perinatal Registry Perinatal Care in the Netherlands 2012 The Netherlands Perinatal Registry, Utrecht (2013)

C.J. Todd, M.C. Farquhar, C. Camilleri-Ferrante Team midwifery: the views and job satisfaction of midwives Midwifery, 14 (1998), pp. 214-224

A. Tong, P. Sainsbury, J. Craig Consolidated criteria for reporting qualitative research (COREQ) Int. J. Qual. Health Care, 19 (6) (2007), pp. 349-357

Tyssen. R., Palmer, K.S., Solberg, I.B., Voltmer, E., Frank, E., 2013.Physicians' perceptions of quality of care, professional autonomy, and job satisfaction in Canada, Norway, and the United States. BMC Serv. Res. 13, 516.

I. van Ham, A.A. Verhoeven, K.H. Groenier, J.W. Groothoff, J. De Haan Job satisfaction among general practitioners: a systematic literature review Eur. J. Gen. Pract., 12 (2006), pp. $174-180$

D. van Hassel, T. Wiegers Cijfers uit de registratie van verloskundigen [Data from the registration of midwives] Tijdschrift voor Verloskundigen, 39 (1) (2014), pp. 31-32

L. van der Hulst Attitude-onderzoek onder verloskundigen [Survey on attitudes among midwives]University of Utrecht, Utrecht (1993)

T.A. Wiegers, B.M. Janssen Monitor Verloskundige zorgverlening, eindrapportage. [Monitor midwifery care; final report] NIVEL, Utrecht (2006)

T.A. Wiegers, J.C. Warmelink, E.R. Spelten, G.M.T. Klomp, E.K. Hutton Workload of primary care midwives in 2010 Midwifery (available online 27 August 2013), 30 (9) (2014), pp. 991997

$\mathrm{Y}$. Zhang, $\mathrm{X}$. Feng The relationship between job satisfaction, burnout, and turnover intention among physicians from urban state-owned medical institutions in Hubei, China: a crosssectional study BMC Health Serv. Res., 11 (2011), p. 235 
About the authors

1. J. Catja Warmelink (catja.warmelink@inholland.nl) is Ph. D. student at the department of Midwifery Science, AVAG and the EMGO Institute for Health and Care Research, VU University Medical Center, Amsterdam, The Netherlands and senior lecturer at the Midwifery Academy Amsterdam-Groningen in Groningen, The Netherlands. She earned her university Master's degree in development psychology at the university of Groningen. Her current research interests include organisation of midwifery care and perinatal psychology.

2. Kirsten Hoijtink (kirstenhoijtink@gmail.com) is a registered nurse and also graduated in 2013 at the Midwifery Academy Amsterdam-Groningen in Groningen, The Netherlands. She is working as a registered primary care midwife now in Raalte, the Netherlands.

3. Marloes Noppers (noppersmarloes@hotmail.com) is a registered nurse and also graduated in 2013 at the Midwifery Academy Amsterdam-Groningen in Groningen, The Netherlands. She is working as a registered primary care midwife now in Utrecht, the Netherlands.

4. Therese A. Wiegers (t.wiegers@nivel.nl) is senior researcher at Netherlands institute for health services research (NIVEL) in Utrecht, the Netherlands. She earned her Ph. D. at the Leiden University. Her current research interest include midwifery care, maternity care and reproductive health.

5. Paul De Cock (paul.decock@inholland.nl) is senior researcher at the department of Midwifery Science, AVAG and the EMGO Institute for Health and Care Research, VU University Medical Center, Amsterdam, The Netherlands and manager and lecturer in psychology at the Midwifery Academy Amsterdam-Groningen in Groningen, the Netherlands. He earned his Ph. D. in epidemiology and mental health at the University of Ulster, Ireland. His current research interests are perinatal psychology and development psychology.

6. Trudy Klomp (trudy.klomp@inholland.nl) is Ph. D. student at the department of Midwifery Science, AVAG and the EMGO Institute for Health and Care Research, VU University Medical Center, Amsterdam, The Netherlands and senior lecturer at the Midwifery Academy Amsterdam-Groningen in Groningen, The Netherlands. She is a registered primary care midwife and earned her university Master's degree in Education Science at the University of Amsterdam (UvA). Her current research interests include labour pain management.

7. Eileen K. Hutton (huttone@mcmaster.ca) is Professor Midwifery Science, AVAG and the EMGO Institute for Health and Care Research, VU University Medical Center, Amsterdam, and Assistant Dean Faculty of Health Sciences, Director Midwifery Education Program and Professor Obstetrics and Gynecology of the McMaster University in Hamilton, Canada and she is a Registered midwife. She earned her Ph. D. in clinical epidemiology at the university of Toronto, Canada. Her current research interest include the quality and organisation of midwifery care. 
About the authors

1. J. Catja Warmelink (catja.warmelink@inholland.nl) is Ph. D. student at the department of Midwifery Science, AVAG and the EMGO Institute for Health and Care Research, VU University Medical Center, Amsterdam, The Netherlands and senior lecturer at the Midwifery Academy Amsterdam-Groningen in Groningen, The Netherlands. She earned her university Master's degree in development psychology at the university of Groningen. Her current research interests include organisation of midwifery care and perinatal psychology.

2. Kirsten Hoijtink (kirstenhoijtink@gmail.com) is a registered nurse and also graduated in 2013 at the Midwifery Academy Amsterdam-Groningen in Groningen, The Netherlands. She is working as a registered primary care midwife now in Raalte, the Netherlands.

3. Marloes Noppers (noppersmarloes@hotmail.com) is a registered nurse and also graduated in 2013 at the Midwifery Academy Amsterdam-Groningen in Groningen, The Netherlands. She is working as a registered primary care midwife now in Utrecht, the Netherlands.

4. Therese A. Wiegers (t.wiegers@nivel.nl) is senior researcher at Netherlands institute for health services research (NIVEL) in Utrecht, the Netherlands. She earned her Ph. D. at the Leiden University. Her current research interest include midwifery care, maternity care and reproductive health.

5. Paul De Cock (paul.decock@inholland.nl) is senior researcher at the department of Midwifery Science, AVAG and the EMGO Institute for Health and Care Research, VU University Medical Center, Amsterdam, The Netherlands and manager and lecturer in psychology at the Midwifery Academy Amsterdam-Groningen in Groningen, the Netherlands. He earned his Ph. D. in epidemiology and mental health at the University of Ulster, Ireland. His current research interests are perinatal psychology and development psychology.

6. Trudy Klomp (trudy.klomp@inholland.nl) is Ph. D. student at the department of Midwifery Science, AVAG and the EMGO Institute for Health and Care Research, VU University Medical Center, Amsterdam, The Netherlands and senior lecturer at the Midwifery Academy Amsterdam-Groningen in Groningen, The Netherlands. She is a registered primary care midwife and earned her university Master's degree in Education Science at the University of Amsterdam (UvA). Her current research interests include labour pain management.

7. Eileen K. Hutton (huttone@mcmaster.ca) is Professor Midwifery Science, AVAG and the EMGO Institute for Health and Care Research, VU University Medical Center, Amsterdam, and Assistant Dean Faculty of Health Sciences, Director Midwifery Education Program and Professor Obstetrics and Gynecology of the McMaster University in Hamilton, Canada and she is a Registered midwife. She earned her Ph. D. in clinical epidemiology at the university of Toronto, Canada. Her current research interest include the quality and organisation of midwifery care. 
1 Box 1. Coding tree: factors associated with primary care midwives' job satisfaction in the

2 Netherlands.

3

4 Job satisfaction

5 1. Contact with clients

$6 \quad$ 1.1. Direct contact with clients

$7 \quad$ 1.2. The satisfaction expressed by the clients

8 2. Cooperation

9

2.1. With immediate colleagues

2.2. Within the healthcare system and with secondary care providers

3. Practice

3.1. Organisation of the practice

3.2. Innovation

3.3. Shared philosophy of care

3.4. Formation

4. The work itself

4.1. Enjoyment

19

4.2. Independence

4.3. Freedom 


\section{Areas for improvement}

2 1. Aspects of the work not directly related to care for clients

3

4

5

6

7

8

9
1.1. Paperwork

1.1.1.Less paperwork

1.1.2.Paperwork performed by someone else

1.2. Cooperation

1.2.1. Within the healthcare system and with secondary care providers

1.2.2. With immediate colleagues

1.2.3. Meetings

1.3. Quality assurance and knowledge translation

1.3.1.Policy agreements and guidelines

1.3.2. More research

1.3.3. More time for quality assurance

1.4. Other

1.4.1. Management

1.4.2. Finances

2. Aspects of work directly related to care for clients

2.1. More personal attention for clients

2.2. More time spent on fewer clients

2.3. Maintain home birth

3. Personal workload

3.1. (reduce) high workload

3.2. Shifts 